\title{
Effect of palatoplasty on speech, dental occlusion issues and upper dental arch in children and adolescents with cleft palate: an integrative literature review
}

\author{
Gabriela Ribeiro Schilling ${ }^{1}$ \\ https://orcid.org/0000-0002-9403-1996 \\ Maria Cristina de Almeida Freitas Cardoso ${ }^{2}$ \\ https://orcid.org/0000-0002-0954-8174 \\ Marcia Angelica Peter Maahs ${ }^{2}$ \\ https://orcid.org/0000-0002-9212-6422
}

Universidade Federal de Ciências da

Saúde de Porto Alegre - UFCSPA,

Programa de Pós-graduação em

Ciências da Reabilitação, Porto Alegre, Rio Grande do Sul, Brasil.

Universidade Federal de Ciências da Saúde de Porto Alegre - UFCSPA, Curso de Fonoaudiologia e Programa de Pósgraduação em Ciências da Reabilitação Porto Alegre, Rio Grande do Sul, Brasil.

Project developed at the Health Sciences Federal University of Porto Alegre - UFCSPA.

Conflict of interests: Nonexistent

\section{(c) (i)}

Received on: August 28, 2018

Accepted on: June 27, 2019

Corresponding address:

Gabriela Ribeiro Schilling

Avenida José Loureiro da Silva,

$\mathrm{n}^{0} 1600 / 408$

CEP: $94010-000$ - Gravataí, Rio Grande do Sul, Brasil

E-mail: gabrielar.schilling@gmail.com

\section{ABSTRACT}

Purpose: to compile acquired knowledge related to speech, maxillary growth, dental arch and dental occlusion issues of subjects with cleft palate (associated or not with cleft lip), relating them to the found structural and morphological changes, along with time of surgery and surgical technique employed in palatoplasty.

Methods: a search was carried out on four databases, namely: PubMed, SciELO, LILACS and MEDLINE, between May and August, 2018. The following descriptors, in Portuguese and in their corresponding terms in English, were used: cleft palate, speech, oral surgery or palatoplasty, teeth or dental arch.

Results: altogether, 92 articles were found in the four databases. Eleven articles met the established selection criteria, thus, included in this review. According to the findings, the palatoplasty surgical technique influences speech, maxillary growth and dental occlusal issues; however, it is still unclear which technique is more beneficial to the subjects with cleft palate.

Conclusion: results found in these 11 studies are divergent in regard to the surgical technique which most favors the development of speech, dental arches and maxillary growth. Therefore, it is important that new researches be carried out relating the aspects of speech, facial growth, dental occlusion and dental arch in the subjects with cleft palate, to the technique and the time of palatoplasty.

Keywords: Surgery; Speech; Cleft Palate; Tooth; Dental Arch 


\section{INTRODUCTION}

The cleft palate $(\mathrm{CP})$ is characterized by the incomplete fusion of the palatine processes happening still in the intrauterine life, between the fourth and twelfth week of pregnancy. This type of cleft is also called post-incisive foramen cleft and may involve different parts of the palate, occurring either totally or partially; it is described according to its extension ${ }^{1}$. It may also be classified as complete, when the hard and the soft palates are affected, or incomplete, when not all the palate is affected ${ }^{2}$. Cleft palate may be associated with cleft lip, when it is called cleft lip and palate, which may be unilateral or bilateral. The CP has an incidence of 0.25 for every 1,000 , varying according to the region of the country ${ }^{3 \cdot 5}$. Cleft lip associated with cleft palate has a prevalence of 0.75 cases for every 1,000 births $^{4}$.

Isolated cleft palates represent $31.7 \%$ of the orofacial clefts diagnosed in a specialized center in Southeast Brazil; in these cases, girls are more often affected ${ }^{1}$. Incomplete cleft palates represent $26.5 \%$ of the total, whereas the complete ones correspond to $5.2 \%$ of the diagnosed clefts ${ }^{1}$. Isolated cleft palates may be divided into five types, according to Freitas et al.': sub mucous, complete, bifid uvula, soft palate, and partial hard palate; these two last ones are the most frequent among the isolated cleft palate. The articles included in this review may present results related to isolated cleft palate or associated with cleft lip.

Studies have demonstrated that the extension of the cleft, and the circumference and length of the maxillary arch influence the growth of this area. Subjects who at birth presented extensive clefts and small circumference and/or length of the maxillary arch had a less favorable maxillary growth, when compared to those with small clefts and big circumference and length of the maxillary $\operatorname{arch}^{6}$. The width of the upper arch in a subject with cleft palate is already smaller when the baby is nine to twelve months old; such maxillary hypoplasia is a common condition among patients with $\mathrm{CP}^{2}$.

Subjects with $\mathrm{CP}$ may have unintelligible speech, distortion when producing phonemes, nasal air escapes, velopharyngeal inadequacy (due to insufficiency or incompetence), hypernasality (excessive resonance in the nasal cavity), glottal stop (plosion of the glottis when producing phonemes), among others ${ }^{7-13}$. Such conditions may affect the social interaction of these people, hindering their communication of ideas and feelings ${ }^{7}$. The palatine deformity in itself, as well as the subsequent surgeries, has a direct relation to craniofacial development, hearing, speech and social relations of the subjects with these characteristics ${ }^{14}$.

Subjects with CP undergo reconstructive surgeries already in their first stage of life, of which palatoplasty is the commonly performed procedure. There are many surgical protocols used with CP patients; however, the ideal surgical technique and time for performing it are still widely discussed in literature ${ }^{9,11}$. Throughout the years, surgical techniques have developed, presenting manifold favorable results for the subjects with cleft ${ }^{2}$. The primary palate surgeries must guarantee the best functional (related to speech) and aesthetic results, with minimum harm to facial growth ${ }^{11,12}$.

Palatoplasty may influence in different ways the development of the anterior part of the maxilla, depending on the extension and type of the cleft; the severity of the cleft is directly proportional to the reduction of dimensions in this rea $^{2}$. Closing the gap in the palate causes impact in maxillary growth, as it creates scar zones that act as barriers for transversal growth $^{12}$. Palatoplasty is not the surgical procedure that contributes the most to reducing the arch width. It may be influenced by lip repair surgery and osteotomy, which may be responsible for the restricted growth of the upper $\operatorname{arch}^{13,15}$.

Due to the structures involved, CP (both isolated and associated to cleft lip) is responsible for speech-related disorders, reducing its intelligibility and resulting in difficulties in oral communication ${ }^{7}$. Regarding the characterization of speech in general terms, there is a greater number of subjects that present alteration in intelligibility of speech, compensatory articulation disorders and hypernasality ${ }^{8}$. In the case of this last one, there is a more serious classification, in which surgical approach is performed at a later time (above two years of age $)^{8}$.

Speech alterations present in CP are considered stigmatizing conditions for the person with the cleft, causing social and psychological embarrassment? Hence, this study aims at gathering the findings related to speech, maxillary growth, dental arch and dental occlusion in subjects with CP (either associated or not with cleft lip), relating them to structural and morphological alterations found in this population at the time when palatoplasty was performed, as well as to the technique used. The purpose of this review is to compile knowledge concerning the abovementioned aspects, in order to clarify the characteristics common to the subjects with $\mathrm{CP}$ (either associated or not with 
cleft lip), and their relation to the reconstructive palate surgical procedure.

\section{METHODS}

The initial step in the development of this review was to formulate the research question: "What is the effect of palatoplasty on speech, dental occlusion issues and upper dental arch measurements in children with cleft palate?" This integrative review used both nationally and internationally published articles ${ }^{16}$.

The following databases were used for this review: PubMed, SciELO (Scientific Electronic Library Online), LILACS (Latin American and Caribbean Literature on Health Sciences), and MEDLINE (Medical Literature Analysis and Retrieval System Online), as they include the majority of the publications on the subject. A manual search was associated with it, going through the references in the selected articles in order to identify other studies that might be included in the review. The articles were researched between May and August, 2018.

The search descriptors, in accordance with the "Health Science Descriptors" (DeCS, from the acronym in Portuguese), were: cleft palate, speech, oral surgery, palatoplasty, teeth, dental arch. The research used the following relation of terms: cleft palate AND (teeth OR dental arch) AND speech AND (oral surgery OR palatoplasty). The search was carried out in Portuguese; in the English language databases, the corresponding English terms were used, as well as the mutual combinations with Boolean operators AND or OR, in accordance with the Medical Subject Headings (MeSH).

Longitudinal and cross-sectional original articles, as well as case series, were analyzed. Certain text types were excluded, namely: opinion articles, editorials, systematic reviews, case reports and dissertations. The selection of articles had the following inclusion criteria: studies dealing with traditional or experimental palatoplasty techniques; researches whose subjects, either having isolated cleft palate or associated with cleft lip, underwent palatoplasty; researches that presented results related to the upper dental arch (and/ or teeth) of subjects with $\mathrm{CP}$, either with or without speech as a secondary outcome; articles published between 2000 and 2018. The exclusion criteria were: researches whose patients had cleft palate associated with syndromes or neurological alterations; studies duplicated in different databases; studies repeated in different languages; review articles; theses; dissertations; editorials; and those whose texts were not available in its entirety.

\section{LITERATURE REVIEW}

A total of 92 articles were found in the four accessed databases, of which 11, those who met the established selection criteria, were included in this review. The results of the search in the databases are available on Figure 1.

ARTICLES FOUND: 92

(PubMed:67; LILACS: 23;

SCIELOQ: 2; MEDLINE: 0)

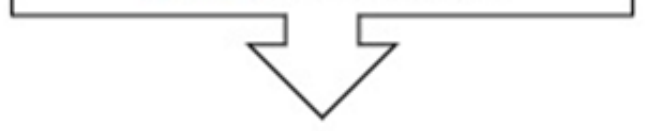

Articles EXCLUDED by reading their titles, abstracts and year. 68

(PubMed:49; LILACS: 18; SCSELLO: 1)

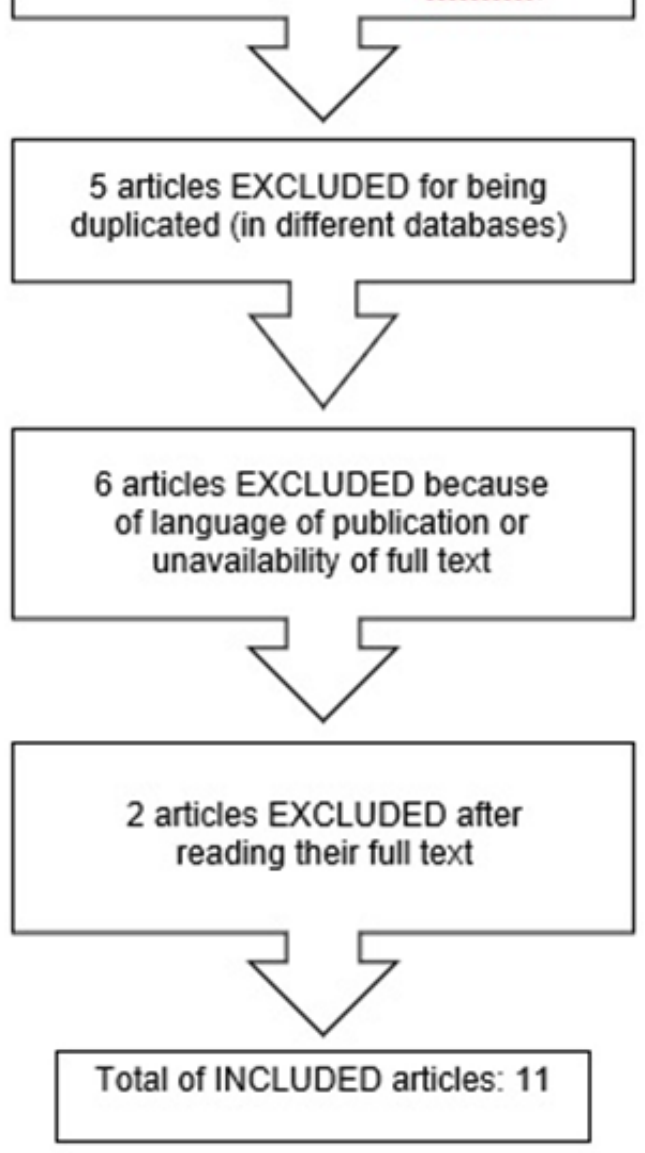

Figure 1. Flowchart of article selection process 
The studies were discrepant as to their aims, methodologies and selected variables. However, most of the researches, comparing different techniques, presented the influence of palatoplasty on speech, dental arch, teeth and/or maxillary growth of subjects with cleft palate, either associated or not with cleft lip. As may be seen on Table 1, studies approaching aspects of speech, dental arch growth and development, and dental occlusion issues, related to palatoplasty, are being carried out in centers of many continents (North and South America, Europe and Asia), demonstrating the prevalence of this condition in the world.

The findings of these articles are described hereafter, with a summary on Table 1.

Table 1. Results with articles selected according to the search strategy developed

\begin{tabular}{|c|c|c|c|c|c|c|c|}
\hline \# & Author & Title & $\begin{array}{c}\text { Year of } \\
\text { publication }\end{array}$ & Country & Participants & Aims & Conclusion \\
\hline 1 & $\begin{array}{c}\text { Carrara CF, } \\
\text { Ambrosio EC, } \\
\text { Mello BZ et al. }{ }^{20}\end{array}$ & $\begin{array}{l}\text { Three- } \\
\text { dimensional } \\
\text { evaluation } \\
\text { of surgical } \\
\text { techniques in } \\
\text { neonates with } \\
\text { orofacial cleft. }\end{array}$ & 2016 & Brazil & $\begin{array}{l}\text { Analysis of } 114 \text { plaster } \\
\text { casts of } 57 \text { children } \\
\text { aged between } 3 \text { and } \\
36 \text { months, divided in } \\
\text { two groups according } \\
\text { to surgical techniques } \\
\text { employed. }\end{array}$ & $\begin{array}{l}\text { To assess the } \\
\text { dimensional } \\
\text { alterations of the } \\
\text { dental arches of } \\
\text { neonates with } \\
\text { unilateral complete } \\
\text { CLP, before and after } \\
\text { one- or two-stage } \\
\text { palatoplasty. }\end{array}$ & $\begin{array}{l}\text { Subjects submitted to lip repair at three } \\
\text { months and one-stage palatoplasty (at } 12 \\
\text { months) presented better anteroposterior } \\
\text { maxillary development, in comparison to } \\
\text { those who underwent associated lip repair, } \\
\text { ala nasi repair and anterior palatoplasty } \\
\text { (at } 3 \text { months) and posterior palatoplasty } \\
\text { at } 12 \text { months. Thus, the authors suggest } \\
\text { that dental arch growth and development } \\
\text { of neonates with cleft lip and palate may } \\
\text { be influenced by the surgical technique } \\
\text { employed, with better results, in this study, } \\
\text { of one-stage palatoplasty. }\end{array}$ \\
\hline 2 & $\begin{array}{l}\text { Dissaux C, } \\
\text { Grollemund B, } \\
\text { Bodin F, et al. }{ }^{12}\end{array}$ & $\begin{array}{l}\text { Evaluation of } \\
\text { 5-year-old } \\
\text { children with } \\
\text { complete cleft } \\
\text { lip and palate: } \\
\text { Multicenter study. } \\
\text { Part 2: Functional } \\
\text { results. }\end{array}$ & 2016 & France & $\begin{array}{l}80 \text { participants } \\
\text { averaging } 5 \text { years } \\
\text { of age at the time of } \\
\text { assessment, } 20 \text { of } \\
\text { them from each center } \\
\text { (10 with unilateral CLP, } \\
10 \text { with bilateral CLP) }\end{array}$ & $\begin{array}{l}\text { To assess functional } \\
\text { results, maxillary } \\
\text { growth and speech } \\
\text { development in } 4 \\
\text { French reference } \\
\text { centers. }\end{array}$ & $\begin{array}{l}\text { The surgical technique performed (two- } \\
\text {-stage palate repair described by Talmant } \\
\text { with Sommerland intravelar veloplasty) } \\
\text { may present less negative impact on ma- } \\
\text { xillary growth and good results on speech } \\
\text { development. Periosteal graft in cleft pa- } \\
\text { late repair was associated with the smaller } \\
\text { number of fistulae in UCLP, but it seems } \\
\text { to have negative impact on anteroposte- } \\
\text { rior maxillary growth. Likewise, one-stage } \\
\text { palatoplasty with Veau-Wardill flap had } \\
\text { negative impact on sagittal and transverse } \\
\text { maxillary growth. It should be noted that, } \\
\text { in each center, surgeries were performed } \\
\text { by the same surgeon. The authors suggest } \\
\text { that further studies need to be carried out. }\end{array}$ \\
\hline 3 & $\begin{array}{c}\text { Navas-Aparício, } \\
\text { MC. }{ }^{19}\end{array}$ & $\begin{array}{l}\text { Maxillary growth } \\
\text { analysis after } \\
\text { surgery in non- } \\
\text { syndromic cleft } \\
\text { palate }\end{array}$ & 2016 & Costa Rica & $\begin{array}{c}5 \text { participants with } \mathrm{CP} \text {, } \\
\text { assessed at } 5 \text { years } \\
\text { of age. }\end{array}$ & $\begin{array}{l}\text { The aim of this study } \\
\text { is to determine } \\
\text { whether there is } \\
\text { impairment in } \\
\text { deficient maxillary } \\
\text { growth, in the } \\
\text { anteroposterior } \\
\text { and transverse } \\
\text { direction, in children } \\
\text { with isolated } \\
\text { nonsyndromic CP. }\end{array}$ & $\begin{array}{l}\text { In this study, palatoplasty was performed } \\
\text { at } 17 \text { months, in average (without speci- } \\
\text { fying the technique). At } 5 \text { years of age, } \\
\text { subjects presented an adequate maxillo- } \\
\text {-mandibular relation, with no growth de- } \\
\text { ficiency in the anteroposterior direction. } \\
\text { However, an asymmetry in transverse } \\
\text { growth of the maxillary arch was noted, } \\
\text { which may have been influenced by the } \\
\text { secondary scarring process of the palate } \\
\text { due to exposure of the bone during sur- } \\
\text { gery. The author suggests that a study be } \\
\text { carried out through different ages of the } \\
\text { child, as the anteroposterior relation may } \\
\text { occur belatedly. }\end{array}$ \\
\hline 4 & $\begin{array}{l}\text { Gundlach KK, } \\
\text { Bardach J, } \\
\text { Filippow D, et } \\
\text { al. }^{13}\end{array}$ & $\begin{array}{l}\text { Two-stage } \\
\text { palatoplasty, is } \\
\text { it still a valuable } \\
\text { treatment protocol } \\
\text { for patients with } \\
\text { a cleft of lip, } \\
\text { alveolus, and } \\
\text { palate? }\end{array}$ & 2013 & $\begin{array}{l}\text { Germany } \\
\text { and USA }\end{array}$ & $\begin{array}{l}\text { Plaster casts of } 85 \\
\text { patients with complete } \\
\text { CLP, assessed at the } \\
\text { ages of } 8 \text { and } 16 \text { years, } \\
\text { in three centers. }\end{array}$ & $\begin{array}{l}\text { Test the importance } \\
\text { of two-stage } \\
\text { palatoplasty on } \\
\text { palatal growth speech } \\
\text { development. }\end{array}$ & $\begin{array}{l}\text { Palatoplasty took place at about } 12 \text { mon- } \\
\text { ths of age and it interferes on growth. } \\
\text { Two-stage palatoplasty would be the high- } \\
\text {-value protocol for subjects with complete } \\
\text { UCLP, which presents lower rates of poste- } \\
\text { rior osteotomies performed. According to } \\
\text { the authors, this would be a good techni- } \\
\text { que regarding speech. }\end{array}$ \\
\hline
\end{tabular}




\begin{tabular}{|c|c|c|c|c|c|c|c|}
\hline \# & Author & Title & $\begin{array}{c}\text { Year of } \\
\text { publication }\end{array}$ & Country & Participants & Aims & Conclusion \\
\hline 5 & $\begin{array}{c}\text { Priya VK, } \\
\text { Reddy JS, } \\
\text { Ramakrishna Y, } \\
\text { Reddy CP. }{ }^{17}\end{array}$ & $\begin{array}{l}\text { Post-surgical } \\
\text { dentofacial } \\
\text { deformities and } \\
\text { dental treatment } \\
\text { needs in cleft-lip- } \\
\text { palate children: a } \\
\text { clinical study. }\end{array}$ & 2011 & India & $\begin{array}{l}50 \text { subjects aged } 3 \text { to } \\
14 \text { years submitted to } \\
\text { lip and palate repair. }\end{array}$ & $\begin{array}{l}\text { To register post- } \\
\text { surgical dentofacial } \\
\text { deformities in } \\
\text { children with CLP, } \\
\text { and to evaluate dental } \\
\text { alterations and other } \\
\text { related problems in } \\
\text { order to develop an } \\
\text { appropriate treatment } \\
\text { plan for oral therapy } \\
\text { and rehabilitation of } \\
\text { these children. }\end{array}$ & $\begin{array}{l}\text { The effect of cleft repair timing on global } \\
\text { development of dentofacial skeletal struc- } \\
\text { tures showed insignificant differences } \\
\text { between the various children with CLP } \\
\text { submitted to surgery. Speech alterations } \\
\text { (not specified) were present in } 92 \% \text { of the } \\
\text { subjects who underwent palatoplasty (with } \\
\text { various techniques). Many dentofacial } \\
\text { anomalies were present in the individuals } \\
\text { due to many factors, such as the type of } \\
\text { surgery performed and growth pattern } \\
\text { under the influence of functional unbalan- } \\
\text { ce of associated structures. The authors } \\
\text { suggest that further longitudinal studies, } \\
\text { with greater number of subjects, must be } \\
\text { developed. }\end{array}$ \\
\hline
\end{tabular}

To compare the result of speech and maxillary growth in children with CLP

Pradel W, repair improves Senf D, Mai speech outcome 6 R, Ludicke $G$ and early Eckelt U, Lauer maxillary growth G. ${ }^{11} \quad$ in patients with cleft lip and palate
24 children with nonsyndromic

2009 Germany unilateral and bilateral CLP or complete cleft palate deformity after palate repair with one- or two-stage procedure, and to identify the best treatment protocol.

Analyses showed a clear relation between the treatment protocol (timing of surgery and palate repair technique), speech outcome and early maxillary growth. One-stage repair, at the age between 9 and 12 months, showed a positive influence on speech development and initial maxillary growth, in contrast with the two-stage procedure.

Palatoplasty with two-stage technique was performed between the ages of 10 and 14 months. Small extension CP cases were treated with simple approach of the palate tissue. The articulation disorders were present in more than $50 \%$ of the children submitted to palatoplasty; likewise, speech intelligibility was considered good or excellent in up to $83 \%$ of the cases. In both cases, regardless of the employed surgical technique, thirty-two percent of the subjects in the research needed orthodontic treatment. Children with CLP presented functional limitations and a variety of conditions that need to be followed up by a multiprofessional team. According to the authors, the otorhinolaryngologist may have an important role in the multidisciplinary team, treating otologic problems and interpreting a series of outcomes (related to phonology, the maxillary arch, and secondary procedures), The multidisciplinary protocol used in the center is effective, with good applicability and low levels of complications.

\begin{tabular}{|c|c|c|c|c|c|c|c|}
\hline & & & & & & & \\
\hline 8 & $\begin{array}{c}\text { Ito S, Noguchi } \\
\text { M, Suda Y et } \\
\text { al. } .^{10}\end{array}$ & $\begin{array}{l}\text { Speech evaluation } \\
\text { and dental arch } \\
\text { shape following } \\
\text { pushback } \\
\text { palatoplasty } \\
\text { in cleft palate } \\
\text { patients: } \\
\text { Supraperiosteal } \\
\text { flap technique } \\
\text { versus } \\
\text { mucoperiosteal } \\
\text { flap technique. }\end{array}$ & 2006 & Japan & $\begin{array}{l}109 \text { participants with } \\
\text { CP (52) and UCLP } \\
\text { (57); } 62 \text { of them were } \\
\text { submitted to pushback } \\
\text { palatoplasty with } \\
\text { supraperiosteal flap } \\
\text { technique, and } 47 \text { with } \\
\text { mucoperiosteal flap } \\
\text { technique }\end{array}$ & $\begin{array}{l}\text { To assess and } \\
\text { compare the shape of } \\
\text { the maxillary dental } \\
\text { arch and speech in } \\
\text { subjects with CP who } \\
\text { underwent pushback } \\
\text { palatoplasty, using } \\
\text { the supraperiosteal } \\
\text { flap technique or the } \\
\text { mucoperiosteal flap } \\
\text { technique. }\end{array}$ & $\begin{array}{l}\text { The findings suggest that pushback pa- } \\
\text { latoplasty (performed, in average, at } 16 \\
\text { months) that uses the supraperiosteal } \\
\text { technique is more advantageous for the } \\
\text { development of speech, when compared } \\
\text { to the mucoperiosteal technique (perfor- } \\
\text { med at } 16 \text { months, in average). The shape } \\
\text { of the dental arch is related to alterations } \\
\text { in speech. Subjects with V-shaped dental } \\
\text { arch had more alterations when compared } \\
\text { to those with U-shaped arch. }\end{array}$ \\
\hline
\end{tabular}




\begin{tabular}{|c|c|c|c|c|c|c|c|}
\hline \# & Author & Title & $\begin{array}{c}\text { Year of } \\
\text { publication }\end{array}$ & Country & Participants & Aims & Conclusion \\
\hline 9 & $\begin{array}{c}\text { Oyama T, } \\
\text { Sunakawa H, } \\
\text { Arakaki K, et } \\
{\text { al. }{ }^{21}}^{21}\end{array}$ & $\begin{array}{l}\text { Articulation } \\
\text { disorders } \\
\text { associated with } \\
\text { maxillary growth } \\
\text { after attainment } \\
\text { of normal } \\
\text { articulation } \\
\text { after primary } \\
\text { palatoplasty for } \\
\text { cleft palate. }\end{array}$ & 2002 & Japan & $\begin{array}{l}22 \text { patients (evaluated, } \\
\text { in average, at } 9.6 \\
\text { years) with UCLP, who } \\
\text { were submitted to one- } \\
\text { stage palatoplasty with } \\
\text { supraperiosteal flap } \\
\text { technique. }\end{array}$ & $\begin{array}{l}\text { The study finds the } \\
\text { paucity of information } \\
\text { regarding the effect } \\
\text { of the alterations } \\
\text { on the dimensions } \\
\text { of the dental arch, } \\
\text { in consequence of } \\
\text { maxillary growth and } \\
\text { the appearance of } \\
\text { articulation disorders } \\
\text { between patients } \\
\text { who had previously } \\
\text { achieved normal } \\
\text { articulation. }\end{array}$ & $\begin{array}{l}\text { With the change in growth of the dimen- } \\
\text { sions of the dental arch, there was an } \\
\text { increase in the occurrence of palataliza- } \\
\text { tion between patients who had already } \\
\text { achieved normal articulation after primary } \\
\text { palatoplasty (performed, in average, at } 21 \\
\text { months). It's important to emphasize that } \\
\text { in the present study, palatalization occur- } \\
\text { red in patients with mixed dentition, who } \\
\text { had smaller anterior palatal volume, lin- } \\
\text { guoversion teeth and worse growth capa- } \\
\text { bility. The findings suggest the importance } \\
\text { of early assessment of the dimensions of } \\
\text { the dental arch and periodic assessment of } \\
\text { speech articulation, even for patients who } \\
\text { achieved normal articulation after primary } \\
\text { palatoplasty. }\end{array}$ \\
\hline
\end{tabular}

Reduction in periosteal damage and time of exposure of the palatal area, from the Cuthbert Veau, to Von Langenbeck, to medial Langenbeck techniques, improved the incisor relations and the articulation.

Pigott RW,

Albery EH,

Albery, three methods of

al. $^{18}$ hard palate repair.
185 cases of unilateral and bilateral complete 2002 UK cleft; the speech of 66 participants with UCLP was assessed.
To compare the outcome in growth, speech and nasal symmetry of three methods of hard palate repair. Seemingly, the improvement in maxillary arch development and the regularity of the hard palate contour diminished the difficulty of the child to position their tongue. According to the authors, this was an unexpected benefit of the medial Langenbeck technique, resulting in significant reduction of articulation alterations. No significant differences were reported between the three techniques concerning nasal air emission, nasal resonance or posterior performance of pharyngoplasty.

In this study, lip repair and soft palate repair were performed simultaneously, between 4 and months of age; palatoplasty with Delaire technique occurred between 12 and 14 months. In the care of children with UCLP and bilateral CLP, the option for

To examine the children before concluding facial

Audit of a multidisciplinary

Webb AA, approach to the

11 Watts R, Read- care of children Ward $\mathrm{E}$ et al. ${ }^{14}$ with unilateral and bilateral cleft lip and palate
15 patients, 8 of whom with UCLP and 7 with bilateral CLP. growth and during
mixed dentition stage.

To evaluate speech, facial appearance, the relations of the dental arches and the lateral cephalometric radiographs. a multidisciplinary protocol and the use of primary surgical techniques (in this case, all performed by the same surgeon), which restored functionality of all structures involved, led to an outcome that requires minimum future intervention and allows these children to achieve almost normal results in terms of appearance, speech, and dental and craniofacial relations. Even though the sample was small in number, It must be recognized that the result, which included both UCLP and bilateral CLP, provided a broader general perspective of the cares related to cleft lip and palate, than that which would be furnished by assessing UCLP alone. 


\section{Speech and palatoplasty}

Speech may be assessed by means of various protocols. Generally, in the selected studies, the subjects were analyzed by professionals clinically experienced in the field. The criteria for intelligibility, articulation disorders, phoneme production distortions, nasal air escape and hypernasality were some of the variables used to measure the outcome of speech-14. It may be influenced by palate reconstruction, a.k.a. palatoplasty, and present alterations in some aspects, such as resonance and articulation. In the study written by Prya et al. ${ }^{17}, 92 \%$ of the subjects, aged 1 to 14 , who underwent palatoplasty (with various techniques) presented alteration in speech (without these alterations being specified) ${ }^{17}$. The most common complications of the palate repair procedure are velopharyngeal insufficiency and oronasal fistulae (which may be either asymptomatic or insufficiency causer $)^{9}$.

A large portion of the children submitted to palatoplasty, independently of the technique used, presented articulation disorders in speech ${ }^{9,17}$. Between the articles used in this review, the established criteria and the names given to speech alteration are heterogeneous and, in some cases, the variables measured to evaluate the outcome are not specified $d^{9-11}$. Subjects' speech intelligibility at 4 years of age, with $\mathrm{CP}$, was considered to be good or excellent in up to $83 \%$ of the cases submitted to two-flap palatoplasty (performed between 10 and 14 months) and in $71 \%$ of the subjects in whom were performed the single-flap approach. However, the influence of the technique was not reported in this outcome; such result, according to the authors is due to the non-randomization of the techniques, tending to use two-flap in CP with greater extension ${ }^{9}$. Nonetheless, the authors attribute the satisfactory results found in two-flap palatoplasty to the technique's precept that aims at excelling in velar muscle adequacy ${ }^{9}$.

The presence of articulation disorders, such as palatalization, glottal stop, low intraoral pressure in producing pressure consonants, nasal air emission and substitutions are common in this population. Palatalization, among those 3 to 5 years old, is more incident in subjects with unilateral cleft lip and palate (UCLP) when compared to subjects with isolated $\mathrm{CP}^{10}$. Subjects with isolated CP present higher incidence of normal speech, in the pre-school and school years, than subjects with UCLP, who underwent pushback palatoplasty, regardless of the technique used ${ }^{10}$. In this study, the average age for performing palatoplasty was 16 months $^{10}$. Subjects with CP who were submitted to supraperiosteal flap pushback palatoplasty, as well as subjects with UCLP submitted to mucoperiosteal flap and supraperiosteal flap, improved their palatalization from pre-school to school stage ${ }^{10}$. Lateral lisp and glottal stop were present in a small portion of the research participants aged 3 to $5^{10}$. These alterations, along with phoneme substitution, were suited when the children reached school age (between 7 and 12 years old $)^{10}$.

In the study by Pradel et al. ${ }^{11}$, speech alterations are classified based on resonance, nasal air escape and compensatory articulation criteria (classified as absent or present, anteriorized or posteriorized, considering the amount of affected phonemes). Agreeing with what has been previously exposed, this study reports that subjects with lip and palate cleft progress in compensatory articulation, as well as in performance of the nose mimetic muscles and in spontaneous speech (classified as normal, intelligible, moderately intelligible and unintelligible), of those aged 4 to 6 . Such result was attributed to the development of the subjects, instead of the surgical procedure used ${ }^{11}$.

Speech may be affected by the surgical technique used in palatoplasty ${ }^{12}$. In literature, many techniques employed in performing this intervention are described $^{9-12}$. Among them, the two-stage palatoplasty with Sommerland intravelar veloplasty presents satisfactory results in the speech outcome (in this study, the Borel-Maisonny Classification scale was used) ${ }^{12}$. Improved results regarding speech may be explained by the dissection of the velar muscle of the hard palate and reconstruction of the velar muscle group of the soft palate, whereas other techniques (direct palatoplasty and Veau-Wardill flap repair) only suture the muscle on the midline, without re-creating the muscle group ${ }^{12}$. It must be taken into account that the one-stage palatoplasty with Veau-Wardill flap technique was performed in a center which was beginning to receive cleft cases, which might have caused a bias ${ }^{12}$.

Pigott et al. ${ }^{18}$ compared three surgical techniques, namely: Cuthbert Veau, von Langenbeck, and medial Langenbeck (performed between 3 and 6 months of age). In this study, 66 children with UCLP were submitted to speech assessment at 5 years of age, in average. In the research, maxillary growth and articulation pattern improved significantly after palate repair. However, nasal symmetry and velopharyngeal function were not changed ${ }^{18}$. Regarding nasal air emission, nasal resonance or pharyngoplasty performed later on, no significant differences were reported between 
the three palatoplasty techniques ${ }^{18}$. Nevertheless, concerning nasal air emission, Von Langenbeck technique presented better results $(77 \%$ of the subjects without nasal air emissions) when compared to medial Langenbeck technique (54\% of the subjects without nasal air emission) ${ }^{18}$. Von Langenbeck technique presented a greater number of children with normal articulation (40.9\%), in comparison to medial Langenbeck technique (27.3\%) and Cuthbert Veau (18.2\%), without statistically significant difference ${ }^{18}$. In the subjects with normal articulation and phonological alteration or immaturity (alterations not related to the cleft, according to the authors), the medial Langenbeck technique presented better results $(68.2 \%)$ than Von Langenbeck (45.5\%) and Cuthbert Veau $(22.7 \%)^{18}$.

Intelligibility, hypernasality and air emission (excluding subjects with oronasal fistula) presented numerically superior results in the subjects who underwent two-stage palatoplasty (performed between 10 and 14 months of age) when compared to those submitted to one-stage approach, though with no statistically significant difference ${ }^{9}$. In this same study, articulation disorders were present in more than half of the evaluated subjects, regardless of the surgical technique used?.

A study has demonstrated that subjects who underwent two-stage surgical procedure, at the ages of 3 and 5 years, presented lower rates of glottal stop ${ }^{13}$. The authors justify it by the subjects' having been intensely submitted to speech-language therapy intervention, at an early age ${ }^{13}$. This same study has shown that subjects submitted to one-stage palatoplasty (between 12 and 18 months) presented better speech indexes (without specifying the analyzed variables) than those who underwent two-stage procedure (at 3 and 5 years), even though there were no statistically significant difference ${ }^{13}$. It should be highlighted that only one part of the subjects (of two of the three participating centers in the study) was assessed by a speech-language pathologist, and not all participants had their speech results presented ${ }^{13}$. Children who underwent one-stage palatoplasty (at 12 months old, in average) presented better results in speech (nasal escape, articulation disorders and facial muscles), at the age of 4 , with statistically significant difference in resonance in comparison to those submitted to two-stage palatoplasty (in average, at 10.5 and 28.3 months) ${ }^{11}$.

Studies report variations regarding results in speech when different surgical techniques are used in subjects with $\mathrm{CP}^{9-11,13}$. It is reported that subjects evaluated between the ages of 7 and 12, submitted to supraperiosteal flaw pushback palatoplasty, presented lower rates of articulation disorders, when compared to subjects submitted to the same procedure, but with the mucoperiosteal flaw technique ${ }^{10}$. In this same research, speech was considered normal when articulation disorders (palatalization, lateral lisp, glottal stop, low intraoral pressure in producing pressure consonants associated with nasal air emission or substitutions) were absent ${ }^{10}$.

Ito et al. ${ }^{10}$ describe low rates of alteration of velopharyngeal function, in the subjects with isolated cleft palate after performing pushback palatoplasty, regardless of the technique used. It should be pointed out that the subjects who presented such alteration used palatal obturator. Velopharyngeal dysfunction may cause hypernasality in speech and nasal air emission when producing consonants ${ }^{10}$. Hypernasality was considered absent or minimal in more than $60 \%$ of the subjects with $\mathrm{CP}$, without statistically significant difference between the surgical techniques employed (one-flap or two-flap palatoplasty) ${ }^{9}$. Similarly, it has been reported in another study that most of the children with CLP who underwent Delaire palatoplasty did not present alteration in nasality and normal speech at the moment when they were assessed (at 7.5 years old, in average) $)^{14}$.

However, another study which assessed resonance and nasal air escape of subjects, at 4 and 6 years of age, has shown statistical difference between the one-stage (performed at 12 months, in average) and two-stage palatoplasty (performed, in average, at 10.5 and 28.3 months) ${ }^{11}$. In this research, at the age of 4 , children who underwent one-stage palatoplasty presented better results (better rates of nasal air escape in producing phonemes, and higher scores of normal resonance) than those who were submitted to two-stage palatoplasty ${ }^{11}$. In spite of presenting improvements in these aspects, at the age of 6 years, the group submitted to two-stage palatoplasty did not reach results as satisfactory as those submitted to one-stage palatoplasty ${ }^{11}$.

In view of the divergence between the results of the researches, it is suggested that the association between speech outcome (hypernasality, nasal air escape, articulation disorders, nose mimetic muscles, glottal stop, intelligibility and distortions in producing phonemes) and the effect of palatoplasty be better explored. Different surgical and evaluative protocols are employed to measure the outcomes, and no pattern between the selected studies has been found. It can be 
inferred from the results that speech is influenced by the surgical technique used. However, it has not been clarified which procedure would be more beneficial in this respect in subjects with $\mathrm{CP}$, based on the 11 studies found. It is further inferred that the type of cleft (isolated CP or CP associated with cleft lip) influences in the speech outcome, since subjects with UCLP presented, in this regard, worse performance than those with isolated CP.

\section{Maxillary growth and palatoplasty}

Age would be an influencing factor in maxillary growth, and transverse maxillary hypoplasia, a common condition among subjects with $\mathrm{CP}^{12}$. The study carried out by Gundlach et al. ${ }^{13}$ has shown that closing the palate at one year of age or before has greater influence on maxillary growth, i.e., subjects submitted to two-stage palatoplasty present better maxillary growth. On the other hand, Pradel et al. ${ }^{11}$ demonstrates that one-stage repair, at the age between 9 and 12 months, has a positive influence on the initial maxillary growth, in contrast with the two-stage procedure. Despite the description of ideal age for performing palatoplasty in the protocols, a study demonstrated that the time when palatoplasty was performed did not present significant effect on global development of dentofacial skeletal structures ${ }^{17}$.

When a subject with CP is submitted to palatoplasty, maxillary growth may present variations, depending on the technique employed; many are the techniques described for this procedure ${ }^{11,12,18}$. Subjects who underwent palatoplasty with Von Langenbeck surgical technique presented better maxillary growth than those submitted to cleft palate repair employing Cuthbert Veau technique. In this regard, medial Langenbeck technique was the one which presented the best results ${ }^{18}$.

Literature presents controversial data concerning the most appropriate palatoplasty technique for the satisfactory transverse maxillary growth. The two-stage palatoplasty technique presented less negative impact on maxillary growth in the study by Dissaux et al. ${ }^{12}$, when associated with Sommerland intravelar veloplasty. The opposite result was found by Pradel et al. ${ }^{11}$ in subjects assessed at the age of six who presented reduction in transverse maxillary growth, when compared to children submitted to one-stage palatoplasty.

One-stage palatoplasty with Veau-Wardill flap surgical technique had a negative impact on transverse maxillary growth, in both anterior and posterior zones, forming a morphologically conic palate in children with $\mathrm{CLP}^{12}$. Nevertheless, it must be emphasized that all cleft palate repair surgical techniques cause transverse maxillary hypoplasia ${ }^{12}$. The negative effect in sagittal growth of the maxilla in subjects with CLP who used Veau-Wardill flap technique was also observed and justified by the transposition of the flap and anchoring on the midline, which may cause resistance in this direction of growth ${ }^{12}$. Periosteal graft in cleft palate repair also seems to have a negative impact on anteroposterior growth of the maxilla; on the other hand, it was associated with the less number of fistulae in UCLP' ${ }^{12}$.

Another study revealed adequate maxillo-mandibular relation in the anteroposterior direction with deficiency in the transverse direction, raising the hypothesis that the transverse maxillary growth may be influenced by the scarring process following surgery, and not only by the technique employed ${ }^{19}$. The study carried out by Faraj et al. ${ }^{2}$ refers to palatoplasty as not being the surgical procedure that most contributed to reducing the width of the arch, for it's already diminished between nine and twelve months of age, therefore prior to the cleft palate repair. Lip repair is considered to be the most responsible for restricted growth of the upper arch in subjects with cleft lip and palate, since it's performed in the first months of life, before palatoplasty ${ }^{15}$.

\section{Dental arch, teeth and palatoplasty}

The study developed by Carrara et al. ${ }^{20}$ suggests that dental arch growth and development in children with CLP may be influenced by the surgical technique employed. A study has demonstrated that the timing of CLP surgical intervention did not present significant effect on global development of dentofacial skeletal structures ${ }^{17}$.

The palate of subjects who underwent one-stage palatoplasty became narrower than that of those who were submitted to the two-stage. Also, those who were submitted to one-stage palatoplasty presented anterior crossbite more frequently than those who underwent the two-stage (at the ages of 3 and 5$)^{13}$. In the study by Prya et al. ${ }^{17}, 12.5 \%$ of children submitted to cleft palate repair aged 1 to 2 years presented anterior crossbite, and $20 \%$ of the cases presented anterior crossbite in those aged 4 to 6 . Most of the subjects with CLP present positive projections of 2 to 3 millimeters ${ }^{14}$. In the study by Vlastos et al. ${ }^{9}, 32 \%$ of the subjects aged between 7 and 12 years needed orthodontic treatment, even though the intervention performed is not specified. 
Most (90\%) of the subjects with CP that underwent pushback palatoplasty with supraperiosteal technique, and $83 \%$ of those with mucoperiosteal technique, presented U-shaped upper dental arch, which is considered an adequate shape for the $\operatorname{arch}^{10}$. When isolated CP subjects are compared to UCLP subjects, both having been submitted to pushback palatoplasty with mucoperiosteal flap technique, there is statistically significant difference, in which subjects with $\mathrm{CP}$ have lower rates of $\mathrm{V}$-shaped dental arches, which is narrower ${ }^{10}$.

\section{Speech, dental arch and palatoplasty}

The occurrence of articulation errors in subjects with CP is related to the shape of the dental arch and the morphology of the hard palate ${ }^{10}$. In mixed dentition stage, palatalized articulation occurs in patients with smaller anterior palatine volume, linguoversion teeth and reduced possibility of growth ${ }^{21}$.

Subjects who presented palatalized articulation disorders present anterior palatine volume and total palatine volume significantly smaller than those with normal articulation ${ }^{21}$. Although both groups present an increase in central palatine width with the increase of maxillary growth, the palatine area decreased a little in the group with palatalization, but increased significantly in the group with normal articulation ${ }^{21}$. Linguoversion teeth are more frequently found in subjects with palatalized articulation disorder, thus suggesting that this position of the teeth may provoke palatalization as it restricts the movements of the tip of the tongue ${ }^{21}$.

Most subjects with isolated CP in the pre-school stage (aged 3 to 5), submitted to pushback palatoplasty, presented speech within normal standards and U-shaped dental $\operatorname{arch}^{10}$. Subjects who presented alteration in speech had V-shaped dental $\operatorname{arch}^{10}$. The shape of the maxillary arch, the alignment of the teeth and the volume of the palatine vault seem to facilitate the development of normal articulation patterns, particularly for the sounds made with the tip of the tongue ${ }^{18}$. The use of two-stage cleft palate repair with Sommerland intravelar veloplasty, employing Talmant technique, presented the best results regarding speech and the least negative impact on maxillary growth ${ }^{12}$.

Subjects with CLP must receive periodic follow-up, in which articulation and dental arch dimensions are assessed, even in those who present normal articulation after primary palatoplasty ${ }^{21}$. Orthodontic treatment performed during mixed dentition is perceived as a way to improve dental arch dimensions, which may prevent the process of palatalization in speech ${ }^{21}$. Approximately $32 \%$ of subjects with CP need to be followed up by an orthodontist in the age between 7 and 12 years ${ }^{9}$.

\section{Future researches}

Many studies suggest that more researches with subjects with CP need to be carried out, both for determining the effect of palatoplasty and its surgical technique on speech and palatal growth, and for relating the aspects of speech, dentition and palatal growth and development in this population $n^{9,12,17,19,21}$.

\section{CONCLUSION}

Although CP is a condition found worldwide, there are few reports in the literature relating aspects of speech, maxillary growth, upper dental arch and dental occlusion issues to palatoplasty, in this type of cleft alone.

Concerning speech, it may be inferred that one- and two-stage palatoplasty presented diverging results, according to this study. Therefore, further studies are necessary in order to compare just these two techniques, without the interference of other factors. In addition, pushback palatoplasty employing supraperiosteal technique presented satisfactory results regarding articulation disorders, when compared to the mucoperiosteal one. Nonetheless, the findings cannot be generalized, due to the restricted amount of studies, as well as the different protocols used.

Maxillary growth may be influenced by the timing and technique of the surgery. In the consulted literature, no technique has been presented with superiorly positive results in all evaluated dimensions of maxillary growth. However, regarding the upper dental arch and dental occlusion issues, it may be concluded that there is a tendency to lower rates of palatal narrowing and anterior crossbite resulting from two-stage palatoplasty - even though it is not possible to assert (because of diverging results and methodologies in the studies) that this palatoplasty technique is the best in cases of CP. More analyses in this population are necessary.

Lastly, based on the findings of this literature review, which resulted in 11 articles meeting the pre-established selection criteria (in accordance with the terms and combinations used in the research), it may be concluded that the palatoplasty surgical technique influences speech, maxillary growth, upper dental arch and dental occlusion issues. Notwithstanding, there is a need for more researches relating palatoplasty 
(when the surgery was performed and which surgical technique was employed) to aspects of speech, maxillary growth, upper dental arch and dental occlusion issues in subjects with $\mathrm{CP}$, centered on longitudinal studies.

\section{REFERENCES}

1. Freitas JAS, Dalben GS, Santamaria Júnior M, Freitas PZ. Current data on the characterization of oral clefts in Brazil. Braz. oral res. 2004;18(2):128-33.

2. Faraj JORA, André M. Alterações dimensionais transversas do arco dentário com fissura labiopalatina, no estágio de dentadura decídua. R Dental Press OrtodonOrtop Facial. 2007;12(5):100-8.

3. Loffredo LCM, Freitas JAS, Grigolli AAG. Prevalence of oral clefts from 1975 to 1994, Brazil. Rev Saúde Pública. 2001;35(6):571-5.

4. Souza J, Raskin S. Estudo clínico e epidemiológico de fissuras orofaciais. J Pediatr. 2013;89(2):137-44.

5. Cunha ECM, Fontana R, Fontana T, Silva WR, Moreira QVP, Garcias GL et al. Antropometria e fatores de risco em recém-nascidos com fendas faciais. Rev Bras Epidemiol. 2004;7(4):417-22.

6. Peltomäki $\mathrm{T}$, Vendittelli BL, Grayson BH, Cutting $\mathrm{CB}$, Brecht LE. Associations between severity of clefting and maxillary growth in patients with unilateral cleft lip and palate treated with infant orthopedics the cleft palate. Craniofacial Journal. 2001;38(6):582-6.

7. Andreoli MA, Yamashita RP, Trindade-Suedam IK, Fukushiro AP. Speech intelligibility after primary palatoplasty: listener perception. Audiol.Commun. Res. 2016;21:e1650.

8. Menegueti KI, Mangilli LD, Alonso N, de Andrade CRF. Speech profile of patients undergoing primary palatoplasty. CoDAS. 2017;29(5):1-10.

9. Vlastos IM, Koudoumnakis E, Houlakis M, Nasika M, Griva M, Stylogianni E. Cleft lip and palate treatment of 530 children over a decade in a single centre. Int J Pediatr Otorhinolaryngol. 2009;73(7):993-7.

10. Ito $S$, Noguchi M, Suda $Y$, Yamaguchi A, Kohama G, Yamamoto E. Speech evaluation and dental arch shape following pushback palatoplasty in cleft palate patients: supraperiosteal flap technique versus mucoperiosteal flap technique. J Craniomaxillofac Surg. 2006;34(3):135-43.

11. Pradel W, Senf D, Mai R, Ludicke G, Eckelt U, Lauer $\mathrm{G}$. One-stage palate repair improves speech outcome and early maxillary growth in patients with cleft lip and palate. J PhysiolPharmacol. 2009;60(8):37-41.

12. Dissaux C, Grollemund B, Bodin F, Picard A, Vazquez MP, Morand $B$ et al. Evaluation of 5-year-old children with complete cleft lip and palate: multicenter study. Part 2: functional results. J Craniomaxillofac Surg. 2016;44(2):94-103.

13. Gundlach KK, Bardach J, Filippow D, Stahl-de Castrillon F, Lenz JH. Two-stage palatoplasty, is it still a valuable treatment protocol for patients with a cleft of lip, alveolus, and palate? J Craniomaxillofac Surg. 2013;41(1):62-70.

14. Webb AA, Watts R, Read-Ward E, Hodgkins J, Markus AF. Audit of a multidisciplinary approach to the care of children with unilateral and bilateral cleft lip and palate. $\mathrm{Br} \mathrm{J}$ Oral Maxillofac Surg. 2001;39(3):182-8.

15. Kramer GJC, Hoeksma JB, Prahl-Andersen B. Early palatal changes after initial palatal surgery in children with cleft lip and palate. Cleft Palate Craniofac J. 1996;33(2):104-11.

16. Mendes KDS, Silveira RCCP, Galvão CM. Integrative literature review: a research method to incorporate evidence in health care and nursing. Texto Contexto Enferm. 2008;17(4):758-64.

17. Priya VK, Reddy JS, Ramakrishna Y, Reddy CP. Post-surgical dentofacial deformities and dental treatment needs in cleft-lip-palate children: a clinical study. J Indian Soc Pedod Prev Dent. 2011;29(3):229-34.

18. Pigott RW, Albery EH, Hathorn IS, Atack NE, Williams $A$, Harland $K$ et al. A comparison of three methods of repairing the hard palate. Cleft Palate Craniofac J. 2002;39(4):383-91.

19. Navas-Aparício MC. Maxillary growth analysis after surgery in non-syndromic cleft palate. Cir Plást Ibero-latinoam. 2016;42(3):247-54.

20. Carrara CFC, Ambrosio ECP, Mello BZF, Jorge PK, Soares S, Machado MAAM et al. Threedimensional evaluation of surgical techniques in neonates with orofacial cleft. Ann Maxillofac Surg. 2016;6(2):246-50.

21. Oyama $T$, Sunakawa $H$, Arakaki $K$, Shinya $T$, Tengan $\mathrm{T}$, Hiratsuka $\mathrm{H}$ et al. Articulation disorders associated with maxillary growth after attainment of normal articulation after primary palatoplasty for cleft palate.Ann Plast Surg. 2002;48(2):138-47. 